\title{
Development of methods for modeling dynamic thermo-hydraulic conditions for assessing the quality of functioning of heat supply systems
}

\author{
Zoya I. Shalaginova ${ }^{1, *}$, and Vyacheslav $V$. Tokarev ${ }^{1}$ \\ ${ }^{1}$ Melentiev Energy Systems Institute of Siberian Branch of the Russian Academy of Sciences (ESI SB \\ RAS), 130 Lermontov Str., Irkutsk 664033, Russia
}

\begin{abstract}
A simulation dynamic model of thermo-hydraulic conditions of heat supply systems (HSS) is presented. The model makes it possible to analyze in time HSS operating conditions with arbitrary configuration and structure, dissimilar loads of heat consumers, taking into account the transport lag of the coolant, cooling along the length of the pipelines, under different weather conditions, disturbances in the system and a given control scenario in the control nodes. To assess the quality, indicators of the degree of heat supply to consumers are proposed. Formulas are given for determining the total, average and average expected deficit (excess) of heat, as well as heat losses in the network, for a calculated period of time under the given control rules. It is proposed to evaluate the efficiency of the operating conditions by the coefficient of efficient use of energy for the billing period. To take into account the real cost of heat, a mathematical model and a method for calculating nodal prices are presented.
\end{abstract}

\section{Introduction}

In developed countries, energy conservation has been given close attention for several decades [1-9]. In Russia, this problem became especially acute in the early 1990s, when, in the emerging market economy, the need arose for direct payments for energy resources. The main reasons for low energy efficiency are energy-wasting technologies, both in production and in transport and heat consumption, lack of economic incentives for the introduction of energy-efficient technologies, lack of systems for accounting and regulation of heat energy, inefficient operating conditions, large heat losses during transport and consumption.

The heat supply system (HSS) of the city is a complicated technological and socio-economic complex that ensures the vital activity of a huge number of consumers. Four factors can serve as a measure for assessing the quality and efficiency of the HSS operating conditions: quality, reliability, cost of heat supply services and ecology. At the same time, in the interests of consumers, the following must be ensured:

- sufficiency of thermal energy to ensure comfort in rooms or for technological processes - quality;

- uninterrupted supply of heat energy - reliability;

* Corresponding author: shalaginova@isem.irk.ru 
- non-burdensome heat energy price - cost;

- safety for public health of the production and transmission processes of heat energy environmental friendliness.

To ensure the listed requirements, in addition to the introduction of new technologies, it is necessary to properly organize the operating conditions of the HSS [12-19]. At the same time, economic efficiency is achieved due to: reduction of circulation flow of network water; optimization of heat supply schedules from sources; reduction of excess heat losses through insulation; reducing the cost of electricity for pumping the coolant. All measures, ultimately, lead to a decrease in fuel and electricity costs $[11,16,19]$.

It is impossible to assess the economic efficiency by stationary models, by the design regime, or by average annual indicators, since at certain points in time the parameters are not maintained, somewhere overheating of premises occurs, somewhere there is a lack of heat. The ISEM SB RAS has developed a simulation model of dynamic thermohydraulic conditions of HSS, which allows simulating the operating conditions of HSS of arbitrary configuration and structure, with different loads of heat consumers, taking into account the transport delay of the coolant, cooling along the length of pipelines, under various weather conditions and disturbances on sources, pumping stations, heat points, consumers and [11,16,20-26].

\section{2. Оценка качества}

\section{Quality control}

The quality of the HSS functioning can be assessed by the quality of heat supply to consumers and the efficiency of the HSS operating conditions [11,16,25].

The heat supply quality to an individual consumer can be estimated by the degree of deviation of the heat amount received by $\operatorname{him} \theta_{i}$, calculated according to the model [25], from the required one $\theta_{i}^{*}$. The degree of provision of the $i$-th consumer at the moment of time $t$ :

$$
\Omega_{i}^{\mathrm{def}}(t)=\left(\theta_{i}^{*}(t)-\theta_{i}(t)\right) \cdot \vartheta, \quad i \in I_{1},
$$

where: $I$ - multitude of pipeline of scheme; $I=I_{1} \cup I_{2} \cup I_{3} ; I_{1}, I_{2}, I_{3}$ - subsets of consumer section, network and sources, respectively; $\vartheta$ - weight coefficient.

$\vartheta=1$, if $\left(\theta_{i}^{*}(t)-\theta_{i}(t)\right)>0$, the consumer has a heat deficit.

$\vartheta=0$, if $\left(\theta_{i}^{*}(t)-\theta_{i}(t)\right) \leq 0$, the consumer is provided with heat energy in the required amount or is in a state of "overheating".

The total deficit of thermal energy of the $i$-th consumer for the calculated period $T$ under the $k$-th scenario of disturbing and control actions:

$$
\Xi_{i}^{\operatorname{def}(k)}=\int_{0}^{T} \Omega_{i}^{\operatorname{def}(k)}(t) d t, \quad i \in I_{1}
$$

When assessing the quality in terms of heat deficit indicators (1)-(2), it is also necessary to take into account the length of time in which the consumer experienced a deficit. Taking into account the accumulating capacity of buildings, indoor temperature may decrease insignificantly, which will not affect the comfort conditions. In normal operation, the allowable period with reduced heat input depends on the accumulating capacity of the building, the category of buildings (residential, public building, etc.) and on the value of the allowable decrease in indoor temperature. The model presented in $[11,25]$ makes it possible to calculate the indoor temperature, taking into account the accumulating capacity of buildings and the time of coolant inflow with certain parameters.

For consumers who allow a decrease in the indoor temperature within certain limits, the 
condition is added to the weight coefficient of formula (1): $\vartheta=1$, if $\left(\theta_{i}^{*}(t)-\theta_{i}(t)\right)>0$, и $\left(C_{\text {in }}^{\mathrm{d}}-C_{\text {in }}\right)>\Delta C_{\text {in }}^{\text {per }}$, the consumer has a heat deficit, taking into account the permissible decrease indoor temperature. Here $C_{\mathrm{in}}^{\mathrm{d}}, C_{\mathrm{in}}, \Delta C_{\mathrm{in}}^{\mathrm{per}}-$ the calculated and current value of the indoor temperature, and the permissible decrease.

Total heat deficit for all consumers under the $k$-th disturbance scenario:

$$
D^{(k)}=\sum_{i \in I_{1}} \Xi_{i}^{\operatorname{def}(k)}
$$

Average deficit for the estimated period $T$ under the $k$-th scenario:

$$
\Xi_{i \mathrm{~m}}^{\operatorname{def}(k)}=\frac{1}{T} \int_{0}^{T} \Omega_{i}^{\operatorname{def}(k)}(t) d t, \quad i \in I_{1}
$$

Repeating the calculations $N$ times for different disturbance scenarios for the given control rules, we can calculate the average expected deficit of the $i$-th consumer:

$$
M\left[\Xi_{i \mathrm{~m}}^{\operatorname{def}(k)}\right]=\frac{1}{N} \sum_{k=1}^{N} \Xi_{i \mathrm{~m}}^{\operatorname{def}(k)}, \quad i \in I_{1}
$$

Dispersion:

$$
\sigma^{2}\left[\Xi_{i \mathrm{~m}}^{\operatorname{def}(k)}\right] \approx \frac{1}{N-1} \sum_{k=1}^{N}\left[\left(\Xi_{i \mathrm{~m}}^{\operatorname{def}(k)}\right)-\left(\frac{1}{N} \sum_{k=1}^{N}\left(\Xi_{i \mathrm{~m}}^{\operatorname{def}(k)}\right)\right)\right]^{2}, \quad i \in I_{1}
$$

The indicators of the excess amount of heat supplied to consumers, integrated over the calculated period of time, are calculated similarly.

Designating for $\theta_{i}^{\mathrm{s}}$ the standard heat losses at the site, and for $\theta_{i}^{\mathrm{c}}$ the losses obtained by calculation, we obtain the values of the excess of heat losses over the standard for each section of the heating network:

$$
\Omega_{i}^{\mathrm{los}}(t)=\left(\theta_{i}^{\mathrm{c}}(t)-\theta_{i}^{\mathrm{s}}(t)\right) \cdot \vartheta, \quad i \in I_{2},
$$

$\vartheta=1$, if $\theta_{i}^{\mathrm{c}}(t)-\theta_{i}^{\mathrm{s}}(t)>0$, insulation condition does not provide standard losses; $\vartheta=0$, if $\theta_{i}^{\mathrm{c}}(t)-\theta_{i}^{\mathrm{s}}(t) \leq 0$, network losses do not exceed the standard.

The total excess of heat losses over the normative ones in the $i$-th pipe for the calculated period $T$ under the $k$-th scenario of disturbing and control actions:

$$
\Xi_{i}^{\operatorname{los}(k)}=\int_{0}^{T} \Omega_{i}^{\operatorname{los}(k)}(t) d t, \quad i \in I_{2} .
$$

The total excess of losses for all network pipes under the $k$-th scenario:

$$
L^{(k)}=\sum_{i \in I_{2}} \Xi_{i}^{\operatorname{los}(k)} .
$$

The second criterion for assessing the quality of the HSS functioning, as noted above, is the efficiency of the conditions, which can be assessed in various ways. One possible approach is to determine the efficiency of energy use.

The coefficient of efficient use of energy according to [11] is the ratio of useful energy to the total amount of consumed energy. If we take as idealized consumer conditions a fully automated input, which can provide the required indoor temperature at any current outdoor temperature, then the useful or consumed energy will represent the required amount of heat at a given outdoor temperature, and consumed energy will be the amount supplied to the heat input energy taking into account "overheating". Taking into account only "overheating" in the last component is explained by the fact that in the event of a deficit, all the energy will be usefully used.

Then the average for the calculated period $T$ the efficiency of energy use by an individual consumer will be determined: 


$$
\eta_{i}=\frac{1}{T} \int_{0}^{T} \frac{\theta_{i}^{*}(t)}{\theta_{i}^{*}(t)+M\left[\Xi_{i_{\mathrm{m}}}^{\mathrm{c}}\right]} d t, \quad i \in I_{1}
$$

Having ranked consumers by this indicator, one can single out consumers who require priority provision of measures to improve controllability. Since in large HSS, measures to synthesize controllability and to provide adjustment measures at a time throughout the entire system require large financial costs, such a ranking of consumers is of practical interest.

The coefficient of efficient use of energy for HSS as a whole will be determined as follows. The total amount of required heat energy for the $i$-th consumer for the estimated period $\mathrm{T}$ under any scenario:

$$
\Xi_{i}^{*}=\int_{0}^{T} \theta_{i}^{*}(t) d t, \quad i \in I_{1}
$$

The total required amount of heat for all consumers:

$$
\theta_{\mathrm{HSS}}^{*}=\sum_{1}^{p} \Xi_{i}^{*}, \quad i \in I_{1}
$$

For the pipelines of the heating network, we will take as idealized conditions the provision of normative heat losses (since it is impossible to transport the coolant completely without heat energy losses). Then the useful energy used for the HSS is determined as the total required amount of heat for all consumers $\theta_{\mathrm{HSS}}^{*}$ and the total normative heat losses at all pipelines of the HSS for the estimated period $L_{\text {los }}^{\mathrm{s}}$. The total excess of the standard heat losses in the network and the total excess amount of heat for all consumers $E^{(k)}$ under the $k$-th scenario of disturbances and given control rules will be referred to energy losses [11].

Then the coefficient of efficient use of energy for the HSS as a whole under the $k$-th scenario of disturbances and given control rules:

$$
\eta_{\mathrm{HSS}}^{k}=\frac{\theta_{\mathrm{HSS}}^{*}+L_{\mathrm{los}}^{\mathrm{s}}}{\theta_{\mathrm{HSS}}^{*}+E^{(k)}+L^{(k)}+L_{\mathrm{los}}^{\mathrm{s}}},
$$

The results obtained with a single reproduction of the process on a simulation model are of a particular nature. Consequently, in order to find one estimate of any characteristic of the functioning of the system, it is necessary to repeatedly "run" the simulation model (to obtain a set of results) with subsequent statistical processing of the data obtained. Therefore, the simulation model must provide means for collecting and means for subsequent statistical processing of data obtained in the course of modeling for the characteristics of the system of interest.

\section{Heat supply service cost}

To take into account the real cost of heat energy, a mathematical model and a methodology for calculating the nodal prices of heat energy have been developed [27, 28]. The cost of heat is determined differentially for individual nodes and consumers of the HSS, taking into account: real flow distribution; location of consumers in the network (distance from the source); the structure and parameters of the network - the presence (absence) of pumping stations on the route of the coolant; the value of heat losses in networks.

The above factors are taken into account using a thermo-hydraulic model [25], on the basis of which the amount of heat in each node is determined, which makes it easy to calculate the real cost of heat energy in all nodes of the HSS.

The proposed approach to calculating nodal prices can be interpreted as a method for solving the problem of distributing the "price field" over the network for a given distribution of heat fluxes. The approach is based on three main provisions: the principle of the nodal 
balance of the cost of heat; the principle of equality of prices for flows flowing from a common node; the principle of differentiated price increment for each of the elements (pipelines) of the calculation scheme.

1) The principle of the nodal balance of the heat cost is described by the equation:

$$
\bar{A}_{\mathrm{s}} Q_{\mathrm{s}} C_{\mathrm{s}}+\bar{A}_{\mathrm{e}} Q_{\mathrm{e}} C_{\mathrm{e}}=Q_{\mathrm{o}} C_{\mathrm{o}}
$$

where $Q_{\mathrm{s}}, Q_{\mathrm{e}}$ - diagonal matrices of order $n$, composed of the quantities of heat at the start and end of the pipelines, respectively; $C_{\mathrm{s}}, C_{\mathrm{e}}-m$-dimensional price vectors at the start and end points of the pipelines, respectively; $C_{\mathrm{o}}-m$-dimensional vector of nodal prices of external inflows (withdrawals) of heat; $Q_{\mathrm{o}}$ - diagonal matrix of order $m$, composed of the values of the amount of heat from external inflows (withdrawals) of heat.

2) The principle of equality of prices for flows outgoing from a common node:

$$
C_{\mathrm{s}}=\overline{A_{\mathrm{s}}^{\mathrm{T}}} C \text {, }
$$

where $C-m$-dimensional vector of prices of mixed flows at nodes.

3) The principle of differentiated price increments for each of the elements (pipelines) of the calculation scheme:

$$
C_{\mathrm{e}}=C_{\mathrm{s}}+\Delta C\left(Q_{\mathrm{e}}\right) .
$$

The vector of price increment for heat transmission $\Delta C\left(Q_{\mathrm{e}}\right)$ is determined from the condition of the financial balance for the pipeline. The cost of heat at the end of the pipeline is greater than the cost at its start by the value of the increment in the cost of pumping the coolant and justified profit for the development of networks:

$$
C_{\mathrm{s}} Q_{\mathrm{s}}+S_{\text {pip }}^{\text {oper }}+S_{\text {pip }}^{\text {los }}+S_{\text {pip }}^{\text {leak }}+S_{\text {pip }}^{\text {pump }}+P_{\text {pip }}=C_{\mathrm{e}} Q_{\mathrm{e}},
$$

where $S_{\text {pip }}^{\text {oper }}, S_{\text {pip }}^{\text {los }}, S_{\text {pip }}^{\text {leak }}, S_{\text {pip }}^{\text {pump }}, P_{\text {pip }}-n$-dimensional vectors of the cost of fixed operating costs, heat losses, leaks, the cost of pumping the coolant and profits by pipelines.

This mathematical model allows calculating differentiated prices for all consumers, taking into account: different costs of heat energy from different sources; variable component for the operation of only those elements of the system that are involved in providing heat to this consumer.

The problem of calculating the distribution of costs to consumers is new, however, the methodology and algorithms for its solution are in many respects similar to the algorithms for calculating the temperature field in the pipeline network, which are used in calculating the HSS conditions [25]. The use of nodal prices of heat energy when calculating the economic efficiency of adjustment measures will allow, in contrast to the calculation of tariffs, to take into account the real costs of generating and transporting heat energy, as well as to determine the feasibility of connecting new consumers at different nodes of the network.

Articles $[29,30]$ present a mathematical model and methodology for calculating the share of heat sources in covering consumers' loads, taking into account nodal prices. In contrast to the methodology for calculating nodal prices [28], for solving this problem, the price of heat is calculated separately for flows coming from different sources. The calculation is performed by constructing matrices of all possible paths leading from the source of heat energy to the consumer. Moreover, the cost of heat supplied to the same consumer, even from one source, but along different routes, can differ significantly due to the component of the transport price. The calculation of equity participation makes it possible to choose the cheapest energy flows in the system to provide specific consumers, which is beneficial for both the energy system and consumers.

In contrast to traditional calculations of economic efficiency, in this case, the cost of annual heat losses, leaks, electricity costs and other components are determined integrally for 
the heating season based on calculations of the dynamic thermohydraulic conditions of HSS.

The research was carried out within the project III.17.4.3 of the Fundamental research program of SB RAS (AAAA-A17-117030310437-4)

\section{References}

1. H. Lund, S. Werner, et al. Energy, 68,1 (2014)

2. Zvingilaite E, Ommen T, et al. 13th International Symposium on District Heating and Cooling, September 3-4, Copenhagen, Denmark (2013)

3. Paulsen O, Fan J, Furbo S, et al. 11th International Symposium on District Heating and Cooling, August 31 to September 2, Reykjavik, ICELAND (2008)

4. M. Vesterlund, J. Dahl. Energy Conversion and Management, 89, 555 (2015)

5. E. Guelpa, C. Toro et al. Energy, 102, 586 (2016)

6. M. Vesterlund, An. Toffolo, Jan Dahl. Energy, 126, 53 (2017)

7. Guelpa E., Sciacovelli Ad., Verda V. Energy, 126,112 (2017)

8. Y. Wang, S. You, et al. Energy, 126, 603 (2017)

9. I. Gabrielaitiene, et al. Energy Conversion and Management, 48, 1, 78 (2007).

10. N.N. Novitsky et al. Pipeline systems in energy sector (Novosibirsk: Nauka, 2008)

11. Shalaginova Z.I. Thermal Engineering. 59, 5, 408 (2012

12. N.N. Novitsky, O.A. Grebneva, et al. Bulletin of RAS. Energy, 2, 12 (2018)

13. N.N. Novitsky, A.V. Alekseev, et al. Proceedings of IrSTU, 22, 11(142), 126 (2018)

14. Shalaginova Z.I., Tokarev V.V. Thermal Engineering. 66, 10, 714 (2019)

15. Novitsky N.N., et al. Radio electronics, informatics, management, 1 (4), 108 (2001)

16. Shalaginova Z.I. Thermal engineering. 61, 11, 829 (2014).

17. Novitsky N.N., et al. Energy of the Tyumen region, 3, 26 (2000)

18. Tokarev V.V., Shalaginova Z.I. Proceedings of IrSTU, 59, 12, 240 (2011)

19. Novitsky N.N., et al., Heat and power efficient technologies, 4, 28 (2000)

20. Novitsky N.N., Alekseev A.V., et al. Energy. T. 184. 151 (2019)

21. A. A. Atavin et al. Pipeline systems in energy sector (Novosibirsk, Nauka, 2017)

22. Grebneva O.A., et al. Proceedings of IrSTU, 3(98), 165 (2015)

23. Shalaginova Z.I. Abstract of the dissertation of the candidate of technical sciences (Irkutsk, ESI SB RAS, 1995)

24. Shalaginova Z.I. Thermal Engineering, 63, 3, 222 (2016)

25. Shalaginova Z.I. Thermal Engineering, 56, 12, 1016 (2009)

26. N.N. Novitsky, Mikhailovsky E.A. et al. Proceedings of IrSTU, 21,9, 157 (2017)

27. N.N. Novitsky et al. Pipeline systems in energy sector (Novosibirsk: Nauka, 2010)

28. Shalaginova Z.I. Thermal Engineering, 65, 10, 756 (2018)

29. N.N. Novitsky et al. Pipeline systems in energy sector (Novosibirsk: Nauka, 2015)

30. Shalaginova Z.I. Proceedings of IrSTU, 21, 11 (130), 144 (2017) 